\title{
Performance of various speckle filter methods in modelling forest aboveground biomass using Sentinel-1 data: case study of Barru Regency, South Sulawesi
}

Wahyu Hendardi Giri Ananto, Ade Febri Sandhini Putri, Haeydar Anggara Hadi, Difa Nisrina Hanum, Bayu Kurnia Puji Wiryawan, et al.

Wahyu Hendardi Giri Ananto, Ade Febri Sandhini Putri, Haeydar Anggara Hadi, Difa Nisrina Hanum, Bayu Kurnia Puji Wiryawan, Rifqi Rizaldy Prabaswara, Sanjiwana Arjasakusuma, "Performance of various speckle filter methods in modelling forest aboveground biomass using Sentinel-1 data: case study of Barru Regency, South Sulawesi," Proc. SPIE 11311, Sixth Geoinformation Science Symposium, 113110P (21 November 2019); doi: $10.1117 / 12.2549036$

EDIE Event: Sixth Geoinformation Science Symposium, 2019, Yogyakarta, Indonesia 


\title{
Performance of Various Speckle Filter Methods in Modelling Forest Aboveground Biomass using Sentinel-1 Data: Case Study of Barru Regency, South Sulawesi
}

\author{
Wahyu Hendardi Giri Ananto ${ }^{1}$, Ade Febri Sandhini Putri ${ }^{1}$, Haeydar Anggara Hadi ${ }^{1}$, Difa \\ Nisrina Hanum ${ }^{1}$, Bayu Kurnia Puji Wiryawan ${ }^{1}$, Rifqi Rizaldy Prabaswara ${ }^{1}$, Sanjiwana \\ Arjasakusuma ${ }^{1}$ \\ ${ }^{1}$ Dept. of Geographic Information Science, Universitas Gadjah Mada, Bulaksumur, \\ Yogyakarta 55281
}

\begin{abstract}
Noise in SAR imagery was produced due to different backscatter responses from the objects in the earth's surface. This resulted in a grainy image, usually known as "salt and pepper" noise, which reduces the capability to identify an object from radar imagery. Therefore, speckle filtering was conducted to decrease this noise from SAR imagery. This study aims to assess the performance of different types of speckle filters, especially when used to construct forest aboveground biomass (AGB) model from Sentinel-1 data in Barru Regency, South Sulawesi. There were 4 filters used in this study i.e. Frost, Gamma-MAP, Median, and Refined Lee. AGB model was constructed by using dual-polarization C-band SAR of Sentinel- 1 data and ground inventory plots. 23 plots were collected in the field and the allometric equation was used to calculate the biomass value of the field survey data then cross-validation models were generated by using biomass value and backscatter data from VV and VH polarization. Quality control was performed by comparing the coefficient of determination $\left(\mathrm{R}^{2}\right)$ of those filters. The result shows that Frost filter, especially on VH polarization was chosen as the best- fit model to estimate the AGB based on the higher value of $\mathrm{R}^{2}(0.3464158)$ and RMSE (33.5231). The result demonstrated the Frost filter as the best filter for retaining and/or enhancing the backscatter signal in Sentinel-1 data to be used in vegetation biophysical modelling.
\end{abstract}

Keywords: Speckle Filtering, Sentinel-1, AGB, Tropical Forest, Cross-validation

\section{INTRODUCTION}

SAR (Synthetic Aperture Radar) is an active microwave imaging radar that produce its own energy without relying on sun illumination ${ }^{[18]}$. Hence, SAR has day and night acquisition capability. Also, SAR can operate in the allweather condition such as penetrating rain and clouds because it uses the microwave band that ranging from 1 to 100 $\mathrm{mm}$ in wavelength ${ }^{[11]}$. Those advantages make SAR images are valuable and important data sources in various application [15]. One application of SAR that widely used is forestry monitoring especially in Above Ground Biomass (AGB) estimation [1] [7] [18] [10] [21]. Above Ground Biomass (AGB) data is one of the key indicators in global carbon accounting to mitigate climate change and biodiversity loss. The launch of the Sentinel 1 satellite that uses C-band $(3,8-7,5 \mathrm{~cm}$ in wavelength) by the European Space Agency (ESA) in 2014 and 2016 has enabled the usage of SAR data in environmental analysis and forest application ${ }^{[21]}$. Sentinel 1 was recorded on a polarimetric system that works with a single polarization of VV and multi-polarization of $\mathrm{VH}$. Polarization is the direction of the electric field of electromagnetic waves and also as the main factor in the interaction between signals and the reflectors ${ }^{[17]}$. This polarization type could influence the backscatter value of vegetation. Difference polarization type of Sentinel-1 can be used to estimate the AGB value ${ }^{[5][8]}$. The advantages of using Sentinel-1 images are easily accessed and free to use. Moreover, Sentinel 1 data is much higher in spatial and temporal resolution compared to other SAR data such as ERS1, ERS-2, JERS, SIR-C/X-SAR, RADARSAT, SRTM, EnviSAT-ASAR, RADARSAR-II, LIGHTSAR, ALOSPALSAR, TerraSAR-X ${ }^{[18]}$.

Sixth Geoinformation Science Symposium, edited by Sandy Budi Wibowo, Andi B. Rimba

Stuart Phinn, Ammar A. Aziz, Proc. of SPIE, Vol. 11311, 113110P - (C) 2019 SPIE

CCC code: $0277-786 X / 19 / \$ 21 \cdot$ doi: $10.1117 / 12.2549036$ 
The quality of SAR images including Sentinel-1 data is reduced with the presence of speckle-a random noise in the form of "salt and pepper" in SAR images. The speckle is generated from the coherent superposition of radar echoes reflected from the earth surface ${ }^{[15]}$. The speckle decreases the ability of SAR to detect targets and obscuring the recognition of spatial patterns ${ }^{[16]}$. Besides, speckle reduces the radiometric quality of the SAR image, thus decreasing the visual quality and accuracy of image interpretation and classification ${ }^{[4]}$. Therefore, the presence of speckles in the SAR image must be reduced before another further analysis. There has been a lot of studies about speckle suppression and reduction.

One type of speckle filtering method that proposed to reduce the noise influence in SAR image is spatial filtering method that relies on the statistical model of the speckle and scenes ${ }^{[11]}$ such as Frost Filter ${ }^{[16]}{ }^{[6]}$, Gamma MAP or Maximum A Posteriori Filter ${ }^{[9]}$, Median Filter [16], Lee Filter ${ }^{[4]}{ }^{[12]}$, and Refined Lee Filter ${ }^{[14]}{ }^{[19]}$. The Frost filter assumes that the pixel of interest value was obtained from replacing the value with a weighted sum of the neighbor pixel values using a moving kernel. Gamma-MAP filter combines geometric and statistical properties to produce the DN values of the pixel and the average DN of neighbor pixel using moving windows. The Median filter could remove the spike and preserve the edges between two different features. Refined Lee Filter is an enhancement of Lee filter and can preserve prominent edges, linear features, point target, and texture information ${ }^{[16]}$. Due to the different processing implemented between the filtering method, the ability of different filtering method in preserving the structural information contained in the backscatter signal should be studied. The structural information in the radar backscatter is important, particularly when used in the vegetation biophysical modeling.

The objective of this research is to assess the performance of different types of speckle filters, especially when used to construct forest aboveground biomass (AGB) model from Sentinel-1 data in Barru Regency, South Sulawesi.

\section{MATERIAL AND METHOD}

\subsection{Study Area}

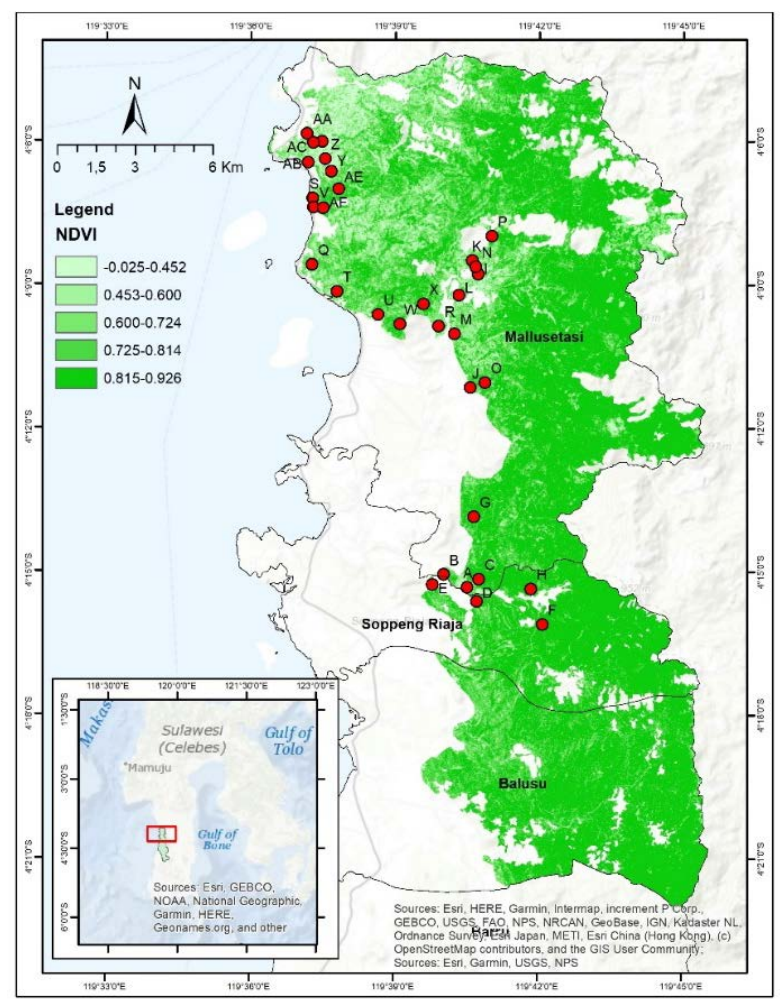

Figure 1. The location of the surveyed forest in Barru Regency, South Sulawesi Province (red dots represent the 32 sample plots). NDVI Images from Sentinel-2 in the background 
Barru Regency is located on the West Coast of South Sulawesi, about $100 \mathrm{~km}$ north of Makassar, Capital City of South Sulawesi. Geographically located in coordinates 405'49" S - 4²47'35" S dan 119³5'00" E - 11949'16" E. The Area of Barru Regency covers an area of 1.174,72 $\mathrm{km}^{2}$, which is divided into 7 districts. Most of Barru Regency is still covered by vegetation, with a dominant ecosystem of tropical rainforest, with function as protected forest ${ }^{[2]}$. Different vegetation cover, various relief conditions and its statues as protected forest make Barru Regency are considered as the study area for AGB estimation. Figure 1. Shows the location of study area that consists of three districts of Barru Regency, i.e. Mallusetasi, Soppeng Raja, and Ballusu.

\subsection{Ground Data}

In total, there are 32 sample plots with a size of $30 \times 30 \mathrm{~m}^{2}$. Field plot size corresponded with a pixel or spatial resolution of Sentinel-1 $(10 \mathrm{~m})$. The field samples were resampled into $30 \times 30 \mathrm{~m}^{2}$ to prevent the dislocation of the center coordinate of the imagery when the measurement was done that may lead to different values of AGB. However, there are only 23 plots that can be used for further analysis. Surveyed plots are located in areas with various vegetation density cover and relief conditions. All ground data were collected from April $22^{\text {nd }}-25^{\text {th }} 2019$. In each plot, the following attribute was measured i.e. diameter at breast height (DBH) using cluster plot type. This plot type consists of several circle subplots in circular combination combined with a $30 \mathrm{~m}$ perpendicular transect. Table 1 . shows the ground data attributes and AGB data. AGB from field data was calculated using the allometric equation for the humid climate with precipitation 1.500-4.000 $\mathrm{mm}^{[3]}$. Y stands for AGB (kg/tree) and D stands for DBH (m).

$$
\mathrm{Y}=42,69-12,8 \mathrm{D}+1,242 \mathrm{D}^{2}
$$

(Source: Brown, 1997)

\subsection{Satellite Data Pre-Processing and Ancillary Data}

Sentinel-1 Synthetic Aperture Radar (SAR) and Sentinel-2 multispectral imagery from the European Space Agency (ESA) used in this study were downloads from the Copernicus Sentinel Scientific Data Hub. Sentinel-1 data is used as the main data for AGB estimation using backscatter value and this data was collected using an interferometric wide swath mode of the VH (vertical transmit-Horizontal receive) and VV (vertical transmit-vertical receive) polarizations. Sentinel- 1 data is acquired on $21^{\text {st }}$ April 2019 which is the closest time to the field data acquisition time. With a pixel size of $10 \mathrm{~m}$, the SAR images are at a high-resolution (HR) level-1 ground range detected (GRD) processing level. The pre-processing steps for Sentinel-1 data consisted of geometric correction using DEMNAS of Barru Regency (9 $\mathrm{m}$ in spatial resolution), speckle filtering using Refined Lee Filter, Frost Filter, Median Filter, and Gamma MAP Filter. The next step is radar calibration using sigma naught. Sentinel 2A is used as ancillary data to determine field samples by the process of classification of vegetation abundance values from vegetation index transformation results. Sentinel 2 imagery acquired on $2^{\text {nd }}$ October 2018 with Level-1C correction (Top of Atmosphere Reflectance). In order to produce images with BOA (Bottom of Atmosphere Reflectance) level, radiometric correction is needed which is assisted by Sen2Cor tools in SNAP software. Before image transformation is performed, the image must go through a resampling process to the size of $30 \times 30 \mathrm{~m}$ to adjust the size of the field sample plot. Image transformation that used is NDVI (Normalized Difference Vegetation Index) which is the transformation of the most established vegetation index. The flowchart of ground data processing and satellite data pre-processing is summarized in Figure 2. 


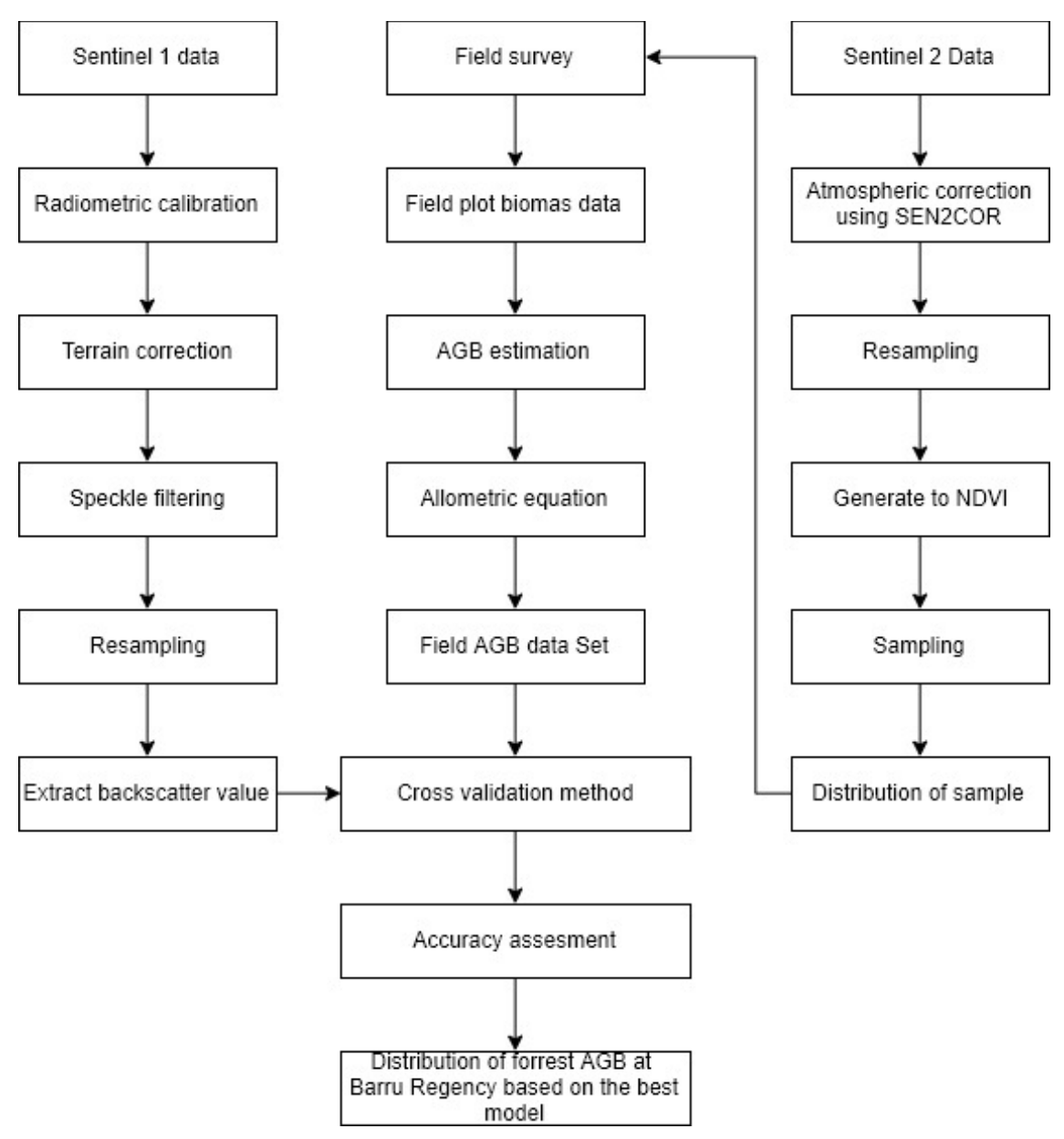

Figure 2. The flowchart of ground data processing and satellite data pre-processing

\subsection{Data Analysis}

Analysis data of SAR Imagery and ground data used linear regression analysis using a single variable. The variable used in the linear regression method was taken from 8 (eight) variables generated from 4 speckle filtering methods implemented to the Sentinel 1's VV and VH polarizations (table 2). Cross-validation was implemented in the linear regression by using 5-folds validation with 100 iterations. The cross-validation analysis used data splitting to generate training data and validation data ${ }^{[10]}$. To assess the prediction ability and the performance of the filtering methods, $\mathrm{R}^{2}$ and RMSE values were used and compared.

\section{RESULTS}

In this research, there were 23 samples taken from 5 vegetation density classes, there are very high, high, medium, low, and very low. All sample was used to model above-ground biomass in Barru Regency. The highest value of aboveground biomass among all samples estimated by using the allometric equation is 165,46 kg/tree (U sample), the lowest aboveground biomass value is 3,81 kg/tree (I sample) and averages off all is 30,60 kg/tree. The variation of the aboveground biomass from all samples can be seen in Table.1. 
Table 1. Variation in the aboveground biomass values in all samples estimated by using an allometric equation

\begin{tabular}{|c|c|c|c|c|c|c|c|}
\hline No & Sample & $\mathbf{X}$ & $\mathbf{Y}$ & $\begin{array}{l}\text { Diameter } \\
\text { (m) }\end{array}$ & $\begin{array}{c}\text { Field Above } \\
\text { ground biomass } \\
\text { (kg/tree) }\end{array}$ & $\begin{array}{c}\text { Field Above } \\
\text { ground } \\
\text { biomass } \\
\text { (Ton/Ha) } \\
\end{array}$ & $\begin{array}{c}\text { Vegetation } \\
\text { Density Class } \\
\text { (NDVI) }\end{array}$ \\
\hline 1 & A & 796935 & 9529064 & 0,151 & 11,44539541 & 0.508 & Very high \\
\hline 2 & $\mathrm{~B}$ & 796306 & 9529252 & 0,372 & 18,16713147 & 1.412 & High \\
\hline 3 & $\mathrm{C}$ & 796605 & 9530815 & 0,188 & 10,86560879 & 0.724 & High \\
\hline 4 & $\mathrm{D}$ & 796986 & 9528766 & 0,152 & 5,52753306 & 0.491 & Medium \\
\hline 5 & $\mathrm{E}$ & 795923 & 9529534 & 0,184 & 33,09035779 & 3.676 & High \\
\hline 6 & $\mathrm{~F}$ & 799698 & 9527522 & 0,192 & 25,62250452 & 9.394 & High \\
\hline 7 & $\mathrm{G}$ & 799282 & 9526518 & 0,276 & 45,54520289 & 13.157 & Very high \\
\hline 8 & $\mathrm{H}$ & 799703 & 9527511 & 0,205 & 26,54318335 & 8.552 & Very high \\
\hline 9 & I & 796354 & 9529074 & 0,194 & 3,814850975 & 0.169 & Very low \\
\hline 10 & $\mathrm{~J}$ & 796778 & 9537129 & 0,194 & 8,021727905 & 0.623 & High \\
\hline 11 & $\mathrm{~N}$ & 799472 & 9527110 & 0,77 & 37,13567972 & 14.441 & Very high \\
\hline 12 & $\mathrm{O}$ & 799546 & 9527344 & 1,754 & 20,16041869 & 7.168 & Very high \\
\hline 13 & $\mathrm{P}$ & 801066 & 9528924 & 0,259 & 109,5404792 & 25.559 & Very high \\
\hline 14 & $\mathrm{Q}$ & 799588 & 9527285 & 0,132 & 13,63078 & 2.120 & High \\
\hline 15 & $\mathrm{~S}$ & 791062 & 9544428 & 0,185 & 10,41661825 & 0.810 & Low \\
\hline 16 & $\mathrm{~T}$ & 791873 & 9540370 & 0,364 & 23,73488045 & 2.109 & Medium \\
\hline 17 & $\mathrm{U}$ & 791721 & 9540411 & 0,283 & 165,4580321 & 36.768 & Very High \\
\hline 18 & $\mathrm{~V}$ & 790965 & 9543885 & 0,259 & 38,32238646 & 9.793 & High \\
\hline 19 & $\mathrm{X}$ & 798356 & 9528715 & 4,944 & 34,05954581 & 6.812 & Very high \\
\hline 20 & $\mathrm{Z}$ & 791176 & 9545634 & 0,186 & 12,28958016 & 0.546 & Low \\
\hline 21 & $\mathrm{AB}$ & 790941 & 9545641 & 0,811 & 5,160517323 & 0.172 & Very low \\
\hline 22 & $\mathrm{AC}$ & 791532 & 9545710 & 0,153 & 11,84552314 & 0.526 & Very low \\
\hline 23 & $\mathrm{AD}$ & 791231 & 9545447 & 0,154 & 33,47847075 & 3.347 & Medium \\
\hline
\end{tabular}

The regression result between field above ground biomass with backscatter of Sentinel 1A imagery dualpolarization $\mathrm{VV}$ and $\mathrm{VH}$ are shown in table 2. The highest determination coefficient $\left(\mathrm{R}^{2}\right)$ was obtained by the combination of Frost filter and VH polarization with a value of 0.35 (RMSE $33.52 \mathrm{~kg}$ ). This indicates that the Frostfiltered VH polarization was able to describe $35 \%$ variance of the aboveground biomass. The frost filter smooth out the noise and retaining edges or shape feature that appropriate with the field condition that has diverse relief ${ }^{[6]}$ also the polarization of VH has horizontal energy is attenuated by the vertical canopy of vegetation especially steams, leaves, branches, or trunks ${ }^{[20]}$. Furthermore, cross-polarization is fewer sensitives to be used in various of the slope, and it is suggested to use cross polarization because it has best performed for monitoring vegetation in mountainous area ${ }^{[20]}$, such as in Barru regency. From the scatter plot (figure 3) can be seen that the VH polarization has a positive correlation that indicates the backscatter value is directly proportional to the biomass value. The Scatter plot also showed some outliers that could reduce the model accuracy. 

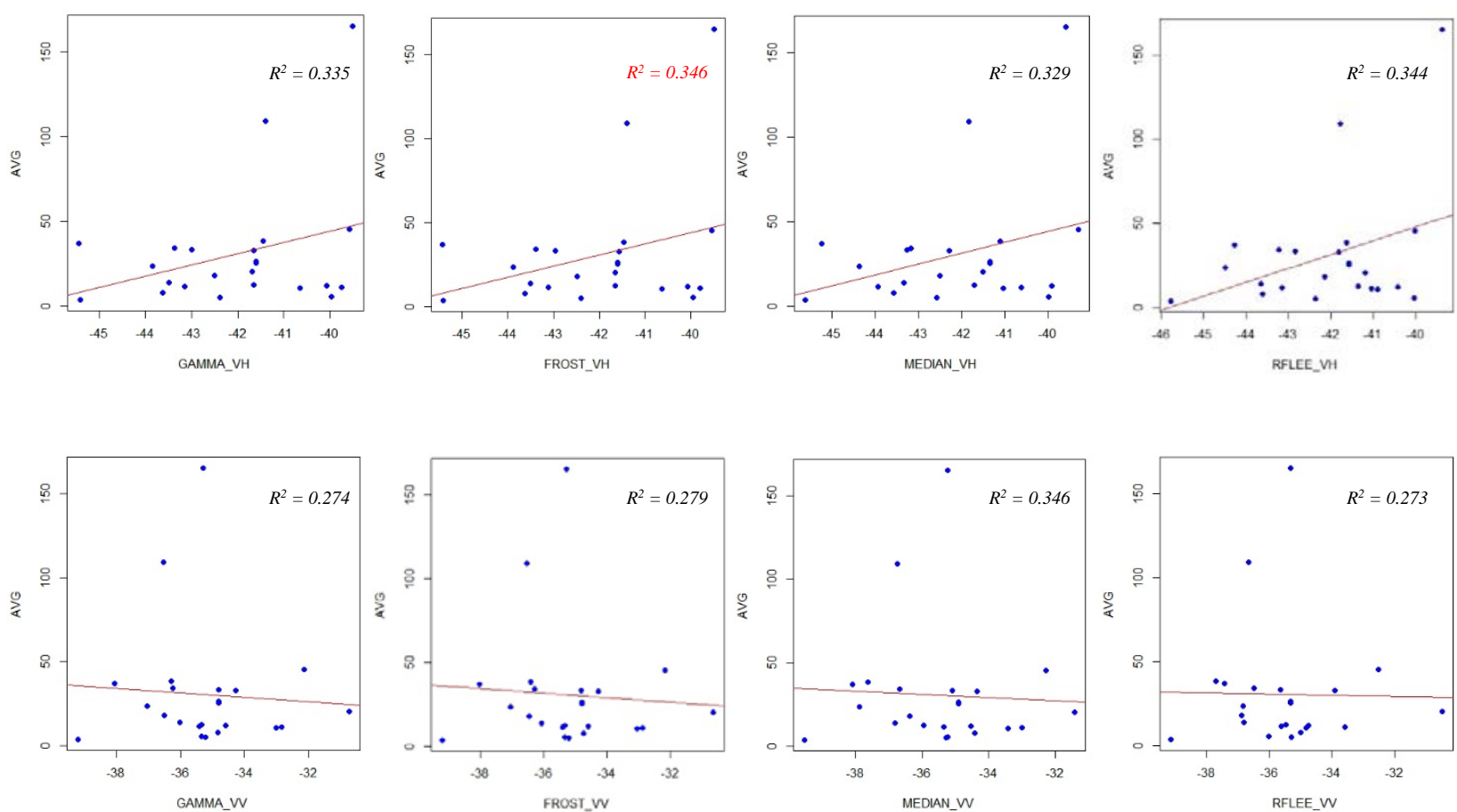

Figure 3: Scatter plot of each model

In addition, from table 2., we also can see that speckle filtered polarization was able to model around $24-35 \%$ of the aboveground biomass. The lowest coefficient of determination was shown by the combination of VV polarization with Median and Refined Lee Filter.

The reverse result was displayed by the RMSE values with VV polarization and Refined Lee with the smallest value of $32.08 \mathrm{~kg}$. This indicated that AGB modeling using VV polarization and Refined Lee filter has the overall lowest deviation although the linear fit is low $\left(\mathrm{R}^{2}\right.$ of 0.27$)$. However, since this study used an overall low number of samples, this result may have resulted from the ability of VV-Refined Lee filtering to fit on the extreme values which then reduced the RMSE values ${ }^{[13]}$. In the future, more samples are needed to justify this result.

Table 2 also revealed a different patterns between VV and VH polarization after being filtered. In overall, there are no significant different in $\mathrm{R}^{2}$ and RMSE values after being processed by different speckle filter. Filtered VV polarization will show in average R2 of $0.273-0.279$, and RMSE from $32.0-32.4 \mathrm{~kg}$ while filtered VH polarization showed $\mathrm{R}^{2}$ in the range of $0.335-0.346$ and RMSE of $33.1-33.7 \mathrm{~kg}$. Here we can say that VH polarization usage in vegetation AGB modeling has been able to predict 6.2 to $7.3 \%$ higher than by using VV polarization with no significant difference in the deviation of AGB modeling $( \pm 1 \mathrm{~kg})$. 
Table 2. Correlation result between AGB from ground data and backscatter value of Sentinel-1 data

\begin{tabular}{|c|c|c|c|}
\hline Speckle Filter & Polarization & $\mathbf{R}^{2}$ & RMSE \\
\hline \multirow{2}{*}{ Gamma } & VV & 0.2746897 & 32.33728 \\
\cline { 2 - 4 } & VH & 0.3353582 & 33.11229 \\
\hline \multirow{2}{*}{ Frost } & VV & 0.279644 & 32.30081 \\
\cline { 2 - 4 } & VH & 0.3464158 & 33.5231 \\
\hline \multirow{2}{*}{ Median } & VV & 0.2734758 & 32.43811 \\
\cline { 2 - 4 } & VH & 0.3291969 & 33.70293 \\
\hline Refined Lee & VV & 0.2732312 & 32.08703 \\
\cline { 2 - 4 } & VH & 0.3449023 & 33.74268 \\
\hline
\end{tabular}

Figure 4. shows the distribution and the condition of aboveground biomass in Barru Regency using Frost FilterVH polarization. The AGB values were divided into 5 classes using natural breaks which are considered as the most representative method to explain the condition of the data. Amount of biomass in Barru Regency dominated by medium class.

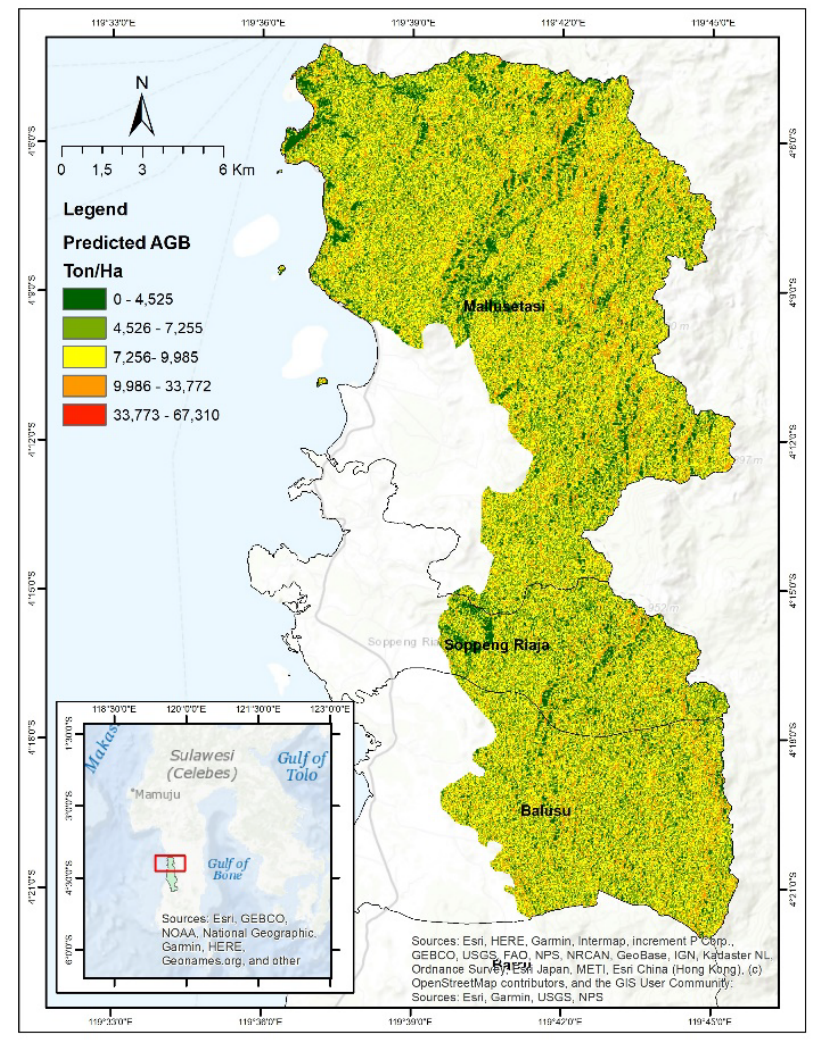

Figure 4. Aboveground Biomass Map of Barru Regency using Frost Filter- Polarization VH

\section{CONCLUSIONS}

Overall, this research shows the capability of four speckle filtering method for Sentinel-1 data to estimate Above Ground Biomass in Barru Regency. The result suggests that the Frost Filter gives the best correlation between AGB and backscatter and the highest accurate value of AGB estimation in Barru Regency with $\mathrm{R}^{2}(0.3464158)$ and RMSE (33.5231). The Frost Filter-VH Polarization Combination is potential to used for AGB estimation in area with same climate condition. 


\section{ACKNOWLEDGMENT}

This research was supported by Department of Geographic Information Science, Faculty of Geography, Gadjah Mada University. All of the author are grateful for finished this research and thank you for being allowed by Barru Regency Goverment to held this research about estimating above ground biomass in Barru Regency. The Sentinel 1A imagery dual Polarization VV and VH was available from Copernicus Scientific Data Hub.

\section{REFERENCES}

[1] Argamosa, R.J.L., Bianco, A.C., Baloloy, A.B., Candido, C.G., Dumalag, J.B.L.C., Dimapilis, L.L.C., Paringit, E.C., "Modelling Above Ground Biomass of Mangrove Forest Using Sentinel-1 Imagery”, ISPRS Annals Int. Developments, Technologies and Application In RS Symp, IV(3), 13-20 (2018).

[2] Badan Pusat Statistik Kabupaten Barru., [Kabupaten Barru dalam Angka 2018], BPS Kabupaten Barru, Barru, South Sulawesi (2018).

[3] Brown, S., [Estimating Biomass and Biomass Change of Tropical Forests: A Primer], FAO Forestry Paper 134 Food and Agriculture Organization of The United Nations, Rome (1997).

[4] Chen, Lin., Ren, Chunying., Zhang, Bai., Wang, Zongming., Xi, Yangbiao., "Estimation of Forest AboveGround Biomass by Geographically Weighted Regression and Machine Learning with Sentinel Imagery”, Forest, 9 (582), 1-20, doi:10.3390/f9100582 (2018).

[5] Debastian A. B., Sanquetta, C. R., Corte, A. P. D., Rex, F. E., Pinto, N. S., "Wvaluating SAR-optical Sensor fusion for aboveground biomass estimation in Brazilian tropical forest," Annals of Fprest Reseach, 62 (1), 109-122 (2019).

[6] Frost, V. S., Stiles, J. A., Shanmugan, K. S., and J. C. Holtzman, “A Model for Radar Images and Its Application to Adaptive Digital Filtering of Multiplicative Noise," IEEE Transactions on Pattern Analysis and Machine Intelligence, 4(2):157-166 (1982).

[7] Frost, V. S., Stiles, J. A., Shanmugan, K. S., Holtzman, J. C., and S. A. Smith, “An Adaptive Filter for Smoothing Noisy Radar Images,” in Proceedings of the IEEE, January 1981, 133-155 (1981).

[8] Huang, Xiaodong., Ziniti, Beth., Torbick, Nathan., Ducey, Mark. J, “Assessment of Above Ground Biomass Estimation Using Multitemporal C-band Sentinel-1 and Polarimetric L-band PALSAR-2 Data,” Remote Sensing, 10 (1424), doi: 10.3390/rs10091424

[9] Jensen, J. R., "Remote sensing of the environment an earth resource perspective: second edition”. England: PEARSON (2014).

[10] Kuan, D.T.; Sawchuk, A.A.; Strand, T.C.; Chavel, P., “Adaptive restoration of images with speckle”, IEEE Trans. Acoust. Speech Signal Process. 35, 373-383 (1987).

[11] Laurin, Gaia Vaglio., Balling, Johannes., Corona, Piermaria., Mattioli, Walter., Papale, Dario., Puletti, Nicola., Rizzo, Maria., Truckenbrodt, John., Urban, Marcel. "Above-ground biomass prediction by Sentinel-1 multitemporal data in central Italy with integration of ALOS2 and Sentinel-2 data," J. Appl. Remote Sens. 12(1), 016008 doi: 10.1117/1.JRS.12.016008 (2018).

[12] Lee, J-S., and Eric Pottier. “Polarimetric Radar Imaging: From Basics to Applications”. New York: CRC Press (2009).

[13] Lee, J-S, and I. Jurkevicj. “ Speckle Filtering of Synthetic Aperture Radar Images: A Review”. Journal of Remote Sensing Review, 8, 313-340 (1994).

[14] Lee, J-S. "Refined filtering of image noise using local statistics”. Comput. Graph. Image Process. 15, 380-389 (1981).

[15] Lopes, A., Nezry, E., Touzi, R., and H. Laur, "Structure Detection and Statistical Adaptive Speckle Filtering in SAR Images,” International Journal of Remote Sensing, 14(9):1735-1758 (1993).

[16] Qiu, F., Berglund, J., Jensen, J., Thakkar, P., \& Ren, D., "Speckle Noise Reduction in SAR Imagery Using a Local Adaptive Median Filter," GIScience \& Remote Sensing, 41(3), 244-266. doi:10.2747/15481603.41.3.244 (2004). 
[17] Sinha, S., Jeganathan, C., Sharma, L., \& Nathawat, M, “A Review of Radar Remote Sensing for Biomass Estimation,” International Journal of Environmental Science and Technology, 12, 1779-1792 (2015).

[18] Torres, R., Snoeij, P., Geudtner, D., Bibby, D., Davidson, M., Attema, E., ... Rostan, F., "GMES Sentinel-1 mission,” Remote Sensing of Environment, 120, 9-24. doi:10.1016/j.rse.2011.05.028 (2012).

[19] Yommy, A. S., Liu, R., \& Wu, A. S., "SAR Image Despeckling Using Refined Lee Filter,” 7th International Conference on Intelligent Human-Machine Systems and Cybernetics, (2015). doi:10.1109/ihmsc.2015.236

[20] Yuan, J., Lv, X., \& Li, R., “A Speckle Filtering Method Based on Hypothesis Testing for Time-Series SAR Images,” Remote Sensing, 10(9), 1383. doi:10.3390/rs10091383 (2018).

[21] Zhao, P., Lu, D., Wang, G., Liu, L., Li, D., Zhu, J., \& Yu, S., "Forest Aboveground Biomass Estimation in Zhejiang Province Using the Integration of Landsat TM and ALOS PALSAR Data,” International Journal of Applied Earth Observation and Geoinformation, 53, 1-15. doi:10.1016/j.jag.2016.08 